\title{
John Dewey y el rescate de la individualidad como nota constitutiva de la forma de vida democrática
}

Jesús David Girado Sierra ${ }^{1}$

Recibido: 9 de noviembre de 2018 / Aceptado: 27 de febrero de 2020

Resumen. Este artículo desarrolla la perspectiva de John Dewey sobre la democracia como una forma de vida que se soporta en la educación del punto de vista, el cuidado de la capacidad de elegir y la inteligencia libre y organizada. Para tal fin, se expone cómo se integran distintos conceptos y propuestas del pragmatista en su rescate de la individualidad como nota constitutiva de una comunidad cooperativa, crítica, abierta y plural.

Palabras Clave: pragmatismo; individualidad; democracia; libertad; educación; autoritarismo.

\section{[en] John Dewey and the rescue of individuality as a constitutive note of the democratic way of life}

Abstract. This paper develops John Dewey's perspective of democracy as a way of life supported by the development of one's own point of view and of one's capacity to choose, that is, on free, organized intelligence. To this end, I show how Dewey's concepts and proposals work together to highlight individuality as a constitutive mark of a cooperative, critical, open, and plural community.

Keywords: pragmatism; individuality; democracy; freedom; education; authoritarianism.

Sumario: 1. Introducción; 2. Rescatar la individualidad es rescatar la democracia; 3. La democracia como modelo de educación de la individualidad; 4. Conclusión; 5. Referencias bibliográficas.

Cómo citar: Girado Sierra, J.D. (2020): "John Dewey y el rescate de la individualidad como nota constitutiva de la forma de vida democrática”, en Revista de Filosofia 45 (2), 413-428.

1 Facultad de Filosofía y Ciencias Humanas

Universidad de La Sabana, Colombia

jesus.girado@unisabana.edu.co 
Me siento inclinado a creer que el corazón y la garantía última de la democracia está en las reuniones libres entre vecinos en las esquinas de las calles, para discutir sus puntos de vista y volver a examinar las noticias de cada día leídas en publicaciones sin censura, y en las conversaciones entre amigos.

John Dewey

\section{Introducción}

Una fuerte imagen en torno a lo que sería el funcionamiento y la legitimación del autoritarismo se muestra en uno de los textos más relevantes de la tradición filosófica. En el libro VII de La República Platón describe cómo un individuo que logra salir de una caverna a la realidad verdadera intenta sacar al resto de hombres que se encuentran prisioneros en ese mundo cavernoso, de sombras y opiniones (Platón, Rep., VII, 514a-517c). Evidentemente, dicho pasaje de La República no funda el autoritarismo y el absolutismo epistemológico y político, sin embargo ofrece una ejemplificación, suficientemente gráfica, para comprender el cómo y el porqué de dicha actitud y proyecto.

$\mathrm{Al}$ interpretar dicho mito es posible decir que tiene como punto de partida la tesis, según la cual, existe una dicotomía evidente entre una realidad poco fiable en la que se sustenta la doxa o la opinión, y otra realidad verdadera (noesis) que se constituye en el fundamento último del conocimiento y de la correcta forma de proceder. Asimismo, se hace evidente que gran parte de los seres humanos, representados por los prisioneros, no son más que habitantes de la caverna, esto es, del mundo de las opiniones o de los difusos ecos de la verdad; y dado que han estado desde niños conformados con ese mundo de sombras o deformado, están propensos a quedar ciegos en caso de atreverse a salir a la luz o la verdad. Ahora bien, algunos de estos prisioneros pudieran, al escapar de las pasiones y las apariencias, percatarse de la ignorancia en la que están el resto de individuos, y entonces gradualmente prepararse para acercarse a la luz, poseer la verdad o conocer el sumo bien. Quienes logren salir de la caverna quedarían automáticamente en una posición de superioridad con respecto al resto: tienen la autoridad moral y epistémica para orientar a quienes aún siguen aferrados a la opinión. Es decir, los poseedores de la verdad saben lo que le conviene a los demás, por ello tienen la obligación de conducirlos como a niños.

En este sentido, no solo la actitud autoritaria y absolutista fundada en la objetividad en cuanto posesión o cercanía a la verdad, sino también, en términos políticos, la autocracia y la aristocracia -incluso la tecnocracia- quedan justificadas en tanto existen individuos que en-verdad saben cómo conducir la historia hacia el bien, esto es, han comprendido que su papel es el de sacar a otros del mundo de la opinión o de las incorrectas formas de justicia. En otras palabras, uno o algunos deben decidir por la mayoría, dado que estos primeros son los únicos capaces de organizarlos de tal forma que se pueda lograr el establecimiento del perfecto orden, sin tomar en consideración las experiencias y opiniones de quienes aún continúan en la caverna. Por esta razón, esta alegoría platónica, en cuanto se configura en un significativo ejemplo de cómo gran parte de la tradición occidental ha pretendido justificar el autoritarismo en cualquiera de sus formas, sea epistemológico, estético, ético, religioso o político, representa todo aquello que rechaza el pragmatismo, en 
la medida en que, de manera antagónica, este último es una constante invitación a defender el punto de vista, la opinión y el consenso, precisamente como antídotos al autoritarismo.

\section{Rescatar la individualidad es rescatar la democracia}

John Dewey dedicó gran parte de su vida intelectual a defender el cultivo de la individualidad como garantía del punto de vista o la opinión, en oposición a la imposición de una verdad absoluta, y como sustento de la democracia concebida como un mundo abierto y plural logrado no solo a través de una forma de gobernar, sino también por medio de un ethos (Bernstein 2010). Es decir, como una forma de vida opuesta a los modelos autocráticos y aristocráticos en los que subyace el autoritarismo en su faceta política, pero sobre todo en clara correspondencia con la educación de cada ciudadano en la delicada tarea de responsabilizarse de las necesidades, problemas y opiniones de los demás. A propósito, afirma Dewey en Democracy and Education in the World Today:

El significado de la democracia, como algo opuesto a toda forma aristocrática de control social y autoridad política, fue muy bien expresado por Abraham Lincoln cuando dijo que ningún hombre era tan bueno ni tan sabio como para gobernar a otros sin su consentimiento, es decir, sin que estos manifiesten sus deseos, necesidades, su concepción en torno a cómo deben conducirse los asuntos sociales y sobre la manera como los problemas sociales deben ser enfrentados. (LW 13: 294-295)

Como se puede apreciar, las consideraciones que hace Dewey sobre la democracia están profundamente ligadas a su concepción en torno a la individualidad, a su valoración del reconocimiento de la particularidad de las personas y de la atención a sus opiniones, en cuanto expresión del punto de vista resultante de su experiencia del mundo. En esta medida, el pragmatista no está tan interesado en realizar un análisis sistemático del diseño de las instituciones sociales y políticas, sino más bien en esclarecer un criterio moral que nos lleve a comprender y mejorar las prácticas sociales y discursivas que configuran a las instituciones (Dewey, Individualism Old and New, LW 5: 41-123). En tal sentido, lo que subyace a su concepción ética de la democracia como una comunidad crítica, abierta y plural, y a su manifiesta defensa de la individualidad y la opinión, no es otra cosa que la revaloración del concepto de libertad. La razón es que, según Dewey, el liberalismo moderno nos legó un sentido de la libertad que es preciso considerar de cara a los cambios históricos y a las distintas expectativas de la sociedad.

La propuesta del "nuevo liberalismo", o de una novedosa concepción de la libertad, es el resultado de una evaluación crítica de las nuevas circunstancias sociales, económicas y políticas a las que los ideales liberales clásicos deben adaptarse. En este horizonte, afirma Matthew Festenstein (1997): "sostiene Dewey que la conexión entre relatividad histórica y el método experimental es intrínseca [...]. La importancia de la individualidad con respecto a políticas sociales se altera con el cambio de las condiciones en que viven los individuos" (p. 65). Así entonces,

2 Los textos citados de originales en inglés fueron traducidos al español por el autor de este artículo. 
el modelo deweyano propone una resignificación de los viejos ideales y valores de la tradición liberal, como punto de partida para comprender la individualidad y la democracia. El soporte teórico lo encuentra en pensadores paradigmáticos de la cultura estadounidense (Pineda 2012, pp. 37-70), tales como Emerson (1928), Whitman (1944) y William James (1984). En estos personajes se encuentra la tesis según la cual lo más relevante en la democracia son los individuos en su individualidad, por encima de los procedimientos o los dispositivos institucionales. Sostiene Dewey en Maeterlinck's Philosophy of Life:

Tal vez Emerson, Walt Whitman y Maeterlinck hayan sido hasta el momento los únicos que, de manera habitual e instintiva, han sido conscientes de que la democracia no es ni una forma de gobierno ni una conveniencia social, sino una metafísica de la relación entre el hombre y su experiencia en la naturaleza. (MW 6: 135)

De hecho, cuando Dewey parte de estos autores para hablar de esa "relación única entre el hombre y su experiencia en la naturaleza", está remarcando el valor que tiene la individualidad como resultado de esa experiencia genuina y distintiva de cada persona, pero también de la libertad como realidad intrínseca, constitutiva y posibilitadora. Mas, la individualidad como diferencia distintiva no se puede tomar como una superficial singularidad, debido a que "no es suficiente por sí misma para dar cuenta de todo aquello que es realmente valioso en la individualidad" (Dewey, Individuality in Education, MW 15: 170). Por tal razón, es preciso entenderla más bien como una realidad valiosa que otorga sentido a la libertad, posibilita el punto de vista y, por tanto, la democracia en tanto forma de vida y no solo régimen político. Afirma el pragmatista en Individuality in Education:

Cuando nos referimos a los individuos humanos tenemos presente el principio de que cada individuo tiene algo que es único e irremplazable. No hay absolutamente nadie que pueda tomar su lugar en el mundo o hacer lo mismo que él hace. Creo que es eso lo que significamos con la idea de igualdad. Con ella no pretendemos decir que las personas son fisiológica o psicológicamente iguales, sino que todo ser humano común tiene algo que lo hace tan distintivo que ningún otro individuo puede sustituirlo. (MW 15: 170-171)

La democracia no puede funcionar como régimen político ni como estilo de vida si no se tiene en cuenta el reconocimiento del valor único de cada individuo y de las consecuencias prácticas que esto implica en la cotidianidad, tales como el desarrollo de una personalidad, la formación de un punto de vista y el ejercicio de virtudes para cultivar una inteligencia auténticamente libre (agencia) que sepa vivir de forma organizada (Dewey 1965). Todo lo anterior cobra sentido por el hecho de que cada individuo experimenta la realidad de manera distinta, y por ello ofrece versiones que deben ser valoradas porque aportan una peculiar tonalidad a los asuntos del mundo humano. En este sentido, solo desde la individualidad puede ser entendida la dimensión positiva de la libertad, de modo que no sea reducida a un asunto meramente jurídico o a una cuestión puramente externa o heterónoma de la persona (Honneth 1999). La individualidad y la libertad, criterios éticos de la democracia según el filósofo estadounidense, deben ser entendidas como "cierta manera de hacer, de pensar y de sentir que desplegamos en cada una de las cosas y que les da su peculiar color, algo que irradia de forma inconsciente la persona a 
través de todos los asuntos de los que se ocupa" (Dewey, Individuality in Education, MW 15: 171). Así pues, la individualidad y la libertad no han de ser entendidas en términos negativos, es decir, como algo que viene dado desde afuera, como producto de lo legislado; no pueden ser entendidas como ausencia de restricciones externas o como margen ofrecido por las prohibiciones. No obstante, el filósofo de la educación previene de lo que un intérprete como Festenstein (1997, p. 65) llama la "zoología mitológica social", esto es, el peligro de la tesis del liberalismo clásico, según la cual, los seres humanos poseen unos derechos naturales individuales, los cuales sirven a su vez como un refuerzo defensivo para contener las arbitrariedades del Estado (Dewey, Individualism Old and New, LW 5: 41-123). En otras palabras, alerta sobre las consecuencias de la concepción que tenía el liberalismo clásico sobre la individualidad y la libertad, debido a que implicaba no solo una concepción negativa de esta última, sino también la creencia en la ley natural que para algunos liberales clásicos se ha transferido a las leyes supuestamente fijas de la economía política, convirtiéndose esto en lo que ha sido llamado la tesis social del liberalismo clásico: "un mercado sin restricciones que expresa el orden natural de las cosas y encarna los medios adecuados para garantizar la libertad individual, mediante la armonización de los diferentes proyectos y planes de vida" (Festenstein 1997, p. 66).

No obstante, la intención de Dewey no es liquidar o desentenderse del liberalismo clásico, se esfuerza en cambio en reinterpretarlo. De hecho, se enfrenta a éste no solo cuestionando su concepción de individualidad, libertad e inteligencia, sino proponiendo una transformación de su tesis social. A partir de esto el estadounidense intenta subrayar su consideración sobre la autonomía, entendida esta desde la libertad individual para la realización de las capacidades, es decir, para el florecimiento de la inteligencia. Ahora bien, la democracia se ve enriquecida con dicha consideración, toda vez que se subraya el cuidado de la individualidad o de la libertad positiva, como presupuesto para que el individuo discierna y elija sus propios proyectos, metas y propósitos. La individualidad en Dewey, recuerda Festenstein (1997, p. 67), consiste en la capacidad personal de elegir, una de las principales actividades características del ser-persona. Sin embargo, no se trata solo de la elección como un proceso primario, resultado de los caprichos o la arbitrariedad, ha de entenderse más bien como una disposición del juicio reflexivo, como el resultado de un proceso avanzado de discernimiento donde se pone en juego la capacidad de crítica de los hábitos, las creencias, los deseos, impulsos y, por tanto, del propio punto de vista sobre la existencia y los asuntos del mundo (Savage 2002). Por supuesto, todo esto implica fomentar hábitos de autoformación, imaginación, análisis, empatía y autocrítica, toda vez que solo gracias a la disposición habitual se logran canalizar las actitudes, modos de comportamiento, pensamientos y, por su puesto, la capacidad de deliberación como ensayo dramático o imaginativo de las distintas posibilidades de ser y sus consecuencias (Dewey 1965; Mougan 2016).

La finalidad es garantizar el crecimiento y la valoración de la expresión de la diversidad de puntos de vista, pues según Rorty (1997) - uno de los más afamados discípulos de Dewey- dicha diversidad es el más claro criterio pragmatista para definir lo bueno, dado que "bueno es solo la libertad, la variedad y el crecimiento" (pp. 14-15); y aclara: “¿crecer para qué? ¿desarrollarse con qué fin? Para crear un mejor futuro, ¿mejor según qué criterio? Mejor en el sentido de que contiene más de lo que consideramos bueno y menos de lo que creemos malo [...] el crecimiento mismo es el único fin moral" (p. 240). Esta consideración rortiana parte de una 
interpretación de la tesis que Dewey propone para subrayar el valor de la diversidad como condición para el disfrute del crecimiento:

La fe en las variadas posibilidades de una experiencia diversificada debe ir acompañada del disfrute del continuo descubrimiento y crecimiento. Ese disfrute es posible incluso en medio de los problemas y los fracasos, siempre y cuando tales experiencias vitales sean tomadas como potenciales revelaciones de significados y valores que deberán ser usados como medios para una más plena y significativa experiencia futura. La creencia en un sentido y propósito únicos distrae al pensamiento y nos lleva a gastar energías que, si fueran dirigidas a la conquista de fines que estuvieran a nuestro alcance, podrían ayudar a que el mundo fuese mejor. (What I Belive. Living Philosophies-VII, LW 5: 272)

Ahora bien, la libertad como ejercicio de la individualidad es condición necesaria para elegir entre las variadas posibilidades de una experiencia diversificada, es decir, es en sí misma agencia en cuanto auténtica acción evaluativa de oportunidades de ser y hacer, mas, no desde el aislamiento o con una actitud individualista, pues solo es posible alcanzar dicho ejercicio con la ayuda de condiciones socio-culturales, económicas y políticas. Dewey pretende hacer entender que existe una integración dinámica o una insospechada simbiosis entre el desarrollo de la autonomía y el funcionamiento adecuado de un entorno social soportado en unas instituciones democráticas que garanticen factores que, a su vez, cuiden un estilo de vida basado en la autorrealización o la creación de sí. En otras palabras, la libertad en su sentido más amplio es solo posible por mor de una forma canónica de orden social o escenario de interacciones reales que debe ser idealmente catalizador del auto-gobierno y la autenticidad, lo cual evita el desarrollo de existencias parasitarias. En tal sentido, puntualiza Dewey en Philosophies of Freedom:

La posibilidad de la libertad está profundamente arraigada en nosotros mismos, pues ella es una única cosa con nuestra individualidad, con ese existir único que hace que seamos lo que somos, y no imitadores o parásitos de otros. Pero, como todas las otras posibilidades, también esta posibilidad tiene que ser actualizada; $y$, también como todas las otras posibilidades, ésta solo puede ser actualizada a través de la interacción con condiciones reales. La cuestión de la libertad política y económica no es un añadido, un agregado de última hora, o, menos aún, una desviación o excrecencia del problema de la libertad personal. Y esto porque las condiciones que forman la libertad económica y política se necesitan en orden a realizar la potencialidad de libertad que cada uno de nosotros lleva consigo en su propia estructura. Las relaciones uniformes y constantes, y su conocimiento en términos de "leyes", no constituyen un impedimento para la libertad, sino que son un factor ineludible para que se convierta en algo efectivo aquello que está en condiciones de crecer en nosotros. (LW 3: 112)

Así entonces, las condiciones socioculturales, políticas y económicas han de ser entendidas como una atmósfera o una plataforma que debe ser propicia para que se dé el autodesarrollo o el crecimiento-de-sí, toda vez que dichas condiciones son construidas desde la autonomía o el disfrute de la libertad como posibilidad para ser. Este aparente fenómeno circular puede comprenderse como una dinámica de cuidadode-sí, de plena creación-de-sí, en cuanto el sí-mismo no ha de entenderse por fuera de las distintas asociaciones que le contribuyen a su realización y, además, porque el 
pragmatista no concibe que alguna persona, desde el disfrute de su individualidad, pretenda anular las condiciones que propicien el desarrollo de su autonomía y, por tanto, la de los otros. No obstante, lograr que los individuos entiendan que la anterior situación sería contradictoria y, por ende, absurda, es el objetivo de la educación que, en cuanto formación de ciudadanos (Festenstein 1997, 57), la misma sociedad debe garantizar con el fin de que estos desarrollen aquella clase de individualidad que es inteligentemente sensible a una vida en común y al reconocimiento de la diversidad de los puntos de vista de los otros. Sobre este asunto remarca Dewey:

Las condiciones sociales interactúan de un modo favorable con las preferencias del individuo (que son su individualidad), en orden a actualizar su libertad, solamente cuando éstos desarrollan inteligencia; y ésta no es ni conocimiento ni pensamiento abstractos, sino poder de visión y reflexión, pues son estas capacidades las que tienen por efecto hacer las preferencias, los deseos y los propósitos más flexibles, perceptivos y decididos. Se ha pensado muy a menudo la libertad como un poder indeterminado que opera en un mundo cerrado y concluido; pero, de hecho, la libertad es una voluntad decidida que está operando permanentemente en un mundo que, en muchos aspectos, es todavía indeterminado, pues permanece abierto y se sigue moviendo hacia un futuro nuevo. (Philosophies of Freedom, LW 3: 113)

Sin embargo, es preciso advertir que no es conveniente interpretar la tesis de Dewey en torno al papel del Estado o de algunas entidades autoritarias suponiendo que estas tienen la responsabilidad de escoger para el individuo un punto de vista o un modo predefinido de desarrollar su individualidad (autorrealizarse). Afirmar esto sería volver a la aceptación de la actitud inicialmente criticada: el autoritarismo. De tal suerte que, descartando la experiencia, los puntos de vista, las opiniones y las decisiones de los individuos en cuanto expresiones de su libertad, se pretenda la existencia de algo o alguien que juzgue como confusas dichas opciones de autorrealización y trate de poner a las personas en el camino correcto, de acuerdo con un criterio externo a ellas. Empero, no es que Dewey esté rechazando las "libertades jurídicas" -la libertad negativa-, lo que sucede es que quiere prevenir una reducción del sentido pleno de la libertad al mero plano de las leyes o de lo heterónomo. Así, el florecimiento humano queda obstaculizado cuando se ignora o ataca el valor de la individualidad, y se obliga a las personas a vivir en una condición parasitaria con respecto al sistema. La meta, por el contrario, es conseguir que las condiciones sociales favorezcan las preferencias del individuo, lo cual no es más que cuidar que cada uno pueda crear su punto de vista, a partir de la experiencia auténtica que tenga de sí mismo y del mundo. En este horizonte, afirma Savage (2002):

Cuando comprendemos, como lo hace Dewey, que el propósito de la comunidad política es liberar a todos los miembros por igual para el autodesarrollo, vemos que el pragmatismo descansa en la suposición de que cada individuo es un fin en sí mismo. Con la excepción de este objetivo final, todos los fines son tentativos porque todos los fines son en sí mismos medios para el bien final del crecimiento. El consecuencialismo pragmático se basa, por lo tanto, no en la mera conveniencia, sino en la necesidad de establecer reglas y deberes relevantes para una búsqueda práctica o concreta de la vida buena. (p. 30) 
Queda claro entonces que: primero, el desarrollo pleno de la individualidad no solo es el presupuesto sino uno de los principales fines de la democracia, debido a que una sociedad que propicie la "pérdida del individuo", es decir, la desestimación o represión de la individualidad, se debe atener a un progreso inauténtico o a su atraso en todos los ámbitos (político, social, cultural, económico, religioso, académico y tecnológico) (Dewey, Individualism Old and New, LW 5: 41-123); y, segundo, que las garantías para el disfrute de la autonomía o la autorrealización son el resultado de la asociación entre individuos que, con puntos de vista diversos, posibilitan el florecimiento humano (Festenstein 2005). Como ya se había advertido, la individualidad no ha de entenderse en Dewey como aislamiento o como esencia inmutable, es por el contrario una constante creación-de-sí en medio de las diversas contingencias, de tal suerte que el individuo hace de sí lo que es por el tipo de asociaciones a las que pertenece. En tal sentido, la auténtica democracia solo puede darse cuando se cuida y promueve la autenticidad del punto de vista del otro, cuando se cree en las potencialidades de los individuos y se garantizan las condiciones para el desarrollo de todo esto. Dewey lo explica en A Critique of American Civilization, de la siguiente forma:

La liberación de las potencialidades individuales, la exaltación de las capacidades personales voluntariamente asociadas, se expresan actualmente de una forma todavía germinal en parangón con el esfuerzo en la dirección opuesta, que es orgánico. La fe nuestra está puesta, en último término, en los individuos y en sus potencialidades. Sin embargo, no hablo de individualismo como algo opuesto a la asociación. Hablo más bien de aquella individualidad que opera en y a través de las asociaciones voluntarias. Si nuestra fachada es la de una organización impuesta externamente, por detrás y bajo ella está operando la fuerza de individualidades liberadas que están experimentando a su modo para hallar y realizar sus propios fines. La historia, a fin de cuentas, da testimonio de que tales fuerzas, aunque germinales y un poco dispersas, son las que en último término prevalecen sobre todas las formas institucionalizadas, aunque puedan parecer estas las más firmemente establecidas. (LW 3: 144)

Se pone en evidencia entonces que el pragmatista no está pensando en la democracia como un simple régimen o un procedimiento mecánico, la concibe más bien como una forma de vida basada en el desarrollo de la individualidad, en el cuidado del ejercicio de la libertad en cuanto creación-de-sí, pero también en la constante formación del propio punto de vista, de la capacidad de autocrítica y el deseo de transformación. Todo esto teniendo como punto de partida el atreverse a imaginar mejores condiciones de vida y, como criterio, la experiencia misma, toda vez que: "lo que el individuo sea efectivamente en su experiencia de vida depende de la naturaleza y el movimiento de la vida asociada" (Dewey, What I Belive. Living Philosophies-VII LW 5: 275). De hecho, en su concepción de la democracia el filósofo de la educación le da gran relevancia a la experiencia individual y al cuidado del punto de vista personal:

No importa cuán ignorante sea una persona, hay algo que sabe mejor que cualquier otra: sabe en qué parte del pie es que más le aprieta el zapato; y puesto que es el individuo el que conoce sus propios problemas, incluso si se trata de alguien poco ilustrado, la idea de democracia - en cuanto opuesta a una concepción aristocrática cualquiera- es que todo 
individuo debe ser consultado de un modo tal que, de forma activa y no solo pasiva, él mismo llegue a formar parte del proceso de la creación de la autoridad y del proceso del control social. (Dewey, Democracy and Education in the World Today, LW 13: 295)

Las consecuencias de esta percepción deweyeana de la democracia, la cual supone la libertad como individualidad y, por ende, le da relevancia a la experiencia y el punto de vista personal, se verán reflejadas en los distintos ámbitos de la acción social cada vez que las necesidades y deseos de los individuos sean tomados en cuenta, al punto en que cada uno se sienta constructor y protagonista de la política social. En consecuencia, tendrá una gran relevancia la consulta mutua y la discusión, con el fin de poner en común y examinar las expresiones individuales de las ideas y los deseos. Por esta razón, el pragmatista defiende fielmente que el control social debe estar democratizado, esto es, debería ser genuinamente público, pues no cree en la captura o centralización del control social y económico por parte del Estado (que en definitiva terminan siendo unos pocos individuos imponiendo su punto de vista). Las consecuencias, aunque puedan resultar bastante idealistas, apuntan a exaltar la inteligencia organizada. Así, desde lo que podría llamarse un socialismo liberal, Dewey sostiene que no solo el monopolio estatal, sino también la anarquía del mercado, representan un insulto a la inteligencia humana. Por tanto, los orígenes de la injusticia ya no serán buscados por Dewey en una naturaleza humana inmutable, sino en las instituciones y los acuerdos que están dentro del control humano deliberado (Festenstein 1997, p. 76).

\section{La democracia como modelo de educación de la individualidad}

El concepto deweyano de inteligencia organizada no excluye la posibilidad de que puedan darse entre las personas conflictos de intereses, en tanto cada una estará tratando de lograr su autorrealización y defendiendo su punto de vista. En este sentido, vale preguntarse ¿cómo armonizar el desarrollo de cada individuo con el mantenimiento de un Estado social en el que las actividades constituyan el bien de los demás? Dewey no se conforma con suponer cierta armonía social entre los distintos proyectos y puntos de vista en confrontación, pues es muy consciente de que los problemas sociales son en muchos casos el claro reflejo de estas fricciones, las cuales, paradójicamente, son el combustible mismo de la democracia:

Esto es precisamente la razón por la que hay una necesidad de democracia: el problema en cuestión es precisamente cuán conflictivas son las reclamaciones que buscan ser resueltas bajo el interés de la mayoría. El método de la democracia -en la medida en que es determinada por la inteligencia organizada- es llevar estos conflictos a la luz pública donde pueden ser vistos, valorados, discutidos y juzgados a la luz de intereses más globales. (Dewey, Democracy and Education in the World of Today, LW 13: 297)

A partir de la defensa de su tesis sobre la inteligencia social u organizada, Dewey no solo evita la reducción de la democracia a un simple procedimiento, a un régimen de gobierno o una maquinaria política, sino que consolida su percepción de la democracia como una forma de vida, como un conjunto de valores e ideales (Festenstein 1997, p. 81). Dewey está convencido de que la democracia no es solo 
un mecanismo de representación donde la libertad es reducida al sufragio, sino más bien el desarrollo de una auténtica autonomía -libertad positiva- y de instituciones transparentes que promuevan la diversidad de puntos de vista como condición del florecimiento humano y de la genuina vida pública. En tal sentido, el filósofo pragmatista se enfrenta a dos grandes concepciones de la democracia ${ }^{3}$ : por un lado a la de Walter Lippman (1927), quien sostiene en su afamado texto The phantom public que la democracia es un mecanismo de representación de los muchos por una élite de técnicos; y, por otra parte, a la tesis de Henry Maine (1886), quien concibe la democracia solo como una forma de gobierno, subrayando el individualismo y, por ende, considerando el consenso público como una unidad artificial derivada de las distintas manipulaciones que hacen ciertos intereses privados. Frente a estas concepciones, Dewey resalta la distinción entre la democracia como un ethos o ideal ético y como un mecanismo político, en la medida en que insiste en que solo puede ser correctamente funcional y adquirir sentido, a partir de una recuperación de la responsabilidad personal en la formación y expresión del punto de vista como resultado de la auténtica individualidad, es decir, de la experiencia diferencial del mundo. En otros términos, la democracia como forma de vida y como régimen político necesita personalidades fuertes, capaces de defender sus puntos de vista y construir, a partir de la escucha de los puntos de vista de otros, proyectos colectivos amplios e inteligentes. Es de esta forma como nace genuinamente lo público como constructo de la soberanía ciudadana. En este horizonte, el ciudadano soberano es un individuo capaz de crear, emitir y defender su propio punto de vista, en cuanto que éste es el resultado de su más íntima experiencia de ser-sí-mismo y de ser-conotros. Es así como nace la inteligencia social u organizada, como consecuencia de la defensa de la reflexión, la voluntad, la opinión y la acción que surgen de una integración dinámica o de la simbiosis entre la experiencia individual del mundo y la realidad pre-fabricada, o las condiciones sociales, políticas, económicas, religiosas, culturales y educativas en las que intenta crecer y florecer la personalidad. En tal sentido, el ciudadano democrático desarrolla una personalidad que no se conforma con conseguir sus caprichos egoístas, sino que es consciente de su existencia en un organismo social más amplio, al cual debe su vida e individualidad y, por ende, en el cual puede poner en consideración de otros su perspectiva a través de su acción participativa y solidaria (Festenstein 2005). Es evidente entonces la defensa que hace Dewey de un individualismo ético al momento de concebir la democracia:

La responsabilidad personal, la iniciativa individual: esas son las notas constitutivas de la democracia. Tanto la aristocracia como la democracia implican que, en su estado actual, la sociedad existe por la búsqueda de realización de un fin que es ético; sin embargo, la aristocracia implica que esto es algo que debe ser hecho primariamente por medio de instituciones u organizaciones especiales que ya existen en la sociedad, mientras que la democracia sostiene que el ideal es algo que ya está funcionando en cada personalidad y que se debe confiar en que cada uno habrá de cuidarlo por sí mismo. Hay, entonces, un individualismo en la democracia que no existe en la aristocracia; pero es un individualismo ético, no numérico; es un individualismo de la libertad, de la responsabilidad, de la

3 Para ampliar la comprensión en torno a las críticas de Dewey a Maine y Lippmann, es preciso remitirse a su texto: The Ethics of Democracy (EW 1: 227-249), y a la reseña que hace del libro The Phantom Public, bajo el título Practical Democracy. Review of Walter Lippman's The Phantom public (LW 2: 213-220). 
iniciativa, que está orientado al logro del ideal ético, no un individualismo anárquico. (The Ethics of Democracy, EW 1: 243)

En otras palabras, la democracia es en sí misma un modelo de educación en el que se aprende que la personalidad es la realidad primera y final. Sumado a esto, la democracia enseña al individuo que la única manera de construir adecuadamente su personalidad es a partir de las posibilidades objetivas que le son presentada en la sociedad. Es decir, las motivaciones y herramientas que se requieren para la realización de la personalidad le vienen al individuo del entorno social. Sin embargo, "la personalidad no le puede ser procurada a alguien, por más degradado y débil que sea, por otro, por más sabio y fuerte que éste sea. Se sostiene también que el espíritu propio de la personalidad habita en cada individuo y que la opción por desarrollarlo debe provenir del propio individuo" (Dewey, The Ethics of Democracy, EW 1: 244). Como es evidente, en las constantes consideraciones de la personalidad que hace el pragmatista se muestran las otras notas constitutivas de la democracia: la libertad, la igualdad y la fraternidad. Ahora bien, estas no son solo consignas para sublevar a las masas, sino las intuiciones morales y políticas más elevada que la humanidad ha logrado, y que cobran mayor sentido al corresponder con la idea de que la individualidad es la nota constitutiva o el tesoro que debe ser mejor resguardado si queremos que se conserven y disfruten el resto de logros en la cultura democrática.

Así entonces, la postura que defiende Dewey no da cabida a las posiciones extremas que conciben la democracia como una simple elección de representantes, los cuales pertenecen a las élites o son tecnócratas (Lippman 1927), lo que los autoriza para pensar por la mayoría e imponer su punto de vista arguyendo que son quienes "han salido de la caverna" y, por tanto, saben lo que a todos conviene (en cuanto poseedores de la verdad). El pragmatista tampoco está de parte de la tesis que entiende la democracia como "gobierno de las masas", donde el individuo es una simple partícula agregada (Dewey, Individualism Old and New, LW 5: 41-123). Igualmente, se opone a aquella postura que sostiene que la defensa y la escucha de los puntos de vista como condición para el consenso público no son más que un acuerdo unificador artificial resultante de las más maquiavélicas manipulaciones que hacen ciertos intereses privados, los cuales terminan por imponerse. Dewey polemiza ${ }^{4}$ estas visiones sobre la democracia y se empecina en mostrarla más bien como inteligencia social y como modelo de educación para la creación no solo de un sentido de la libertad individual, sino de cierta identidad de intereses. Festenstein (1997) analiza esta tesis deweyana de la siguiente manera:

Los hombres no son átomos aislados no sociales, sino que son hombres en cuanto entran mediante relaciones intrínsecas unos con otros, y el Estado por su parte representa a los hombres en la medida en que han establecido orgánicamente una relación con otros, o poseen una unidad común de propósito e interés [...] La democracia como una forma de organización social es el ideal de desarrollo político, pues representa un organismo completo donde el individuo es la expresión de la totalidad, sin la intervención de intereses de clase. (p. 80)

4 Un análisis más actual de esta polémica es posible rastrearla en el excelente texto de Diego Pineda (2012), en el artículo de Ignacio Redondo (2006) o en la introducción a la traducción española del texto The Public and Its Problems, hecha por Ramón del Castillo (2004). 
La necesaria relación de la educación con la democracia como organización social se justifica en la medida en que es condición de posibilidad para que se formen ciudadanos para la libre discusión, la crítica y la imaginación de mejores escenarios sociales. Asimismo, gracias a esta necesaria relación entre educación y democracia las personas se hacen responsables de la inteligencia social, es decir, de la organización del desarrollo político que logre el mejor modo de vida posible. Ahora bien, educar al individuo en condiciones democráticas para que cultive su punto de vista como expresión de su individualidad es posible, según el pragmatista, porque dicha aspiración ya ha estado funcionando en cada personalidad haciéndose hábito. Por tanto, se debe confiar en que cada individuo deseará cuidar ese modo de vida donde puede ser auténticamente libre y bien educado para aportar su originalidad a la pluralidad existente en el mundo humano.

Aún más, la educación de los hábitos en la deliberación permite la transformación social. "De lo que se trata es de modificar los hábitos para conseguir que la democracia se convierta en un modo de vida, de promover las condiciones sociales que hacen posible la existencia de ciudadanos virtuosos" (Mougan, 2016, 98). Así entonces, frente a un problema social o político lo que se necesita no es una nueva teoría política verdadera que nos saque de la caverna, sino una buena formación del habitus ciudadano. De hecho, la educación en y para la democracia se convierte en la mejor estrategia para evitar el autoritarismo y el totalitarismo en cualquiera de sus dimensiones. En tal sentido, la defensa de la tesis según la cual la educación para el desarrollo de la autonomía y la inteligencia crítica es una expresión de la democracia como forma de vida, es imprescindible para sortear consideraciones pesimistas frente al proyecto de formar una ciudadanía soberana o competente que participe-delibere sobre los intereses comunes. Uno de los que pone en duda el poder transformador del hábito y del punto de vista informado y creativo del ciudadano es Lippman (1927), justificando que "no se debe cargar a cada ciudadano con la opinión de expertos en todas las cuestiones, sino poner esa responsabilidad fuera de él, en un administrador responsable" (p. 250).

La postura de Lippman, evidentemente tecnocrática, reduce la democracia a su mínima expresión, ya que propone conformarse con una mínima libertad para la información y una esporádica participación para determinar quién o quiénes, entre los más instruidos, deliberarán sobre el destino de la mayoría. Ahora bien, es obvio que la educación que recibe el ciudadano no puede ser concebida ingenuamente como purificada y auténticamente formadora de un punto de vista crítico y creativo; lo cierto es que existen élites que filtran y acomodan la información que sirve para la formación del individuo. Dicho fenómeno condena a cierta trampa que imposibilita las transformaciones sociales que a todos convienen, razón por la cual ha sido estudiado en detalle bajo denominaciones tales como distorsión comunicativa (Habermas 1970; 1989; 1997), manipulación discursiva (Sartori 1998), dominio de interpretaciones (Vattimo 1990; Castells 2009) o imposición de bases representacionales (Van Dijk 2012; 2003). Sin embargo, la forma de hacer frente a dicha realidad, según Dewey, no es la propuesta por Lippman (1927, p. 251), quien propone que los individuos se resignen a la tecnocracia o a cierta democracia conducida por élites que saben lo que a todos nos conviene. El filósofo de la educación subraya una vez más que no se puede reducir la democracia a un simple procedimiento o a una maquinaria política, pues la democracia es ante todo un ideal de vida basado en la libertad, la creación-de-sí, la autocrítica y el respeto de la diversidad de puntos de vista, lo cual ha de promover 
la tolerancia y la solidaridad de los individuos -y las maquinarias políticas-en todas y cada una de las formas de asociación como la familia, la educación, el trabajo, la economía y la religión.

Ahora bien, Dewey al cuidar y valorar la especial relación de la educación con la democracia está señalando la importancia del fomento de un tipo particular de personalidad formada en virtudes como la prudencia -en cuanto disposición a la escucha para poseer un panorama más amplio de las distintas perspectivas- y la tolerancia, las cuales son imprescindibles como garantías de auténticos debates públicos, esto es, para la confrontación argumentativa y la persuasión ${ }^{5}$, pero también para lograr "una sociedad integrada cooperativamente que intenta solucionar sus propios problemas" (Honneth 1999, p. 85). La asimilación de la democracia como el mejor ideal de vida asociada lograda hasta este momento por los seres humanos, supone entonces la formación de las personas en el uso de la fuerza argumentativa para proponer su punto de vista, rechazando la violencia como forma para imponer sus propias creencias. En consecuencia, una cultura democrática de este tipo requiere como supuesto psicológico y moral el ejercicio de la prudencia, la tolerancia y la solidaridad, con el fin de desarrollar una personalidad capaz de valorar la crítica y los puntos de vista alternativos, concibiendo sus propios intereses en una forma que tenga en cuenta los intereses y las opiniones de otros participantes (Festenstein 1997, p. 88).

Esta idea del apoyo recíproco entre la democracia y la formación resulta bastante sólida, pues presenta no solo un esquema de cuidado de un modo de vida basado en la dinámica de la creación-de-sí y el desarrollo de la propia experiencia, sino también un genial intento de unir dos ideas que se podrían concebir a simple vista como antagónicas: la preocupación por el cultivo de la propia individualidad (inteligencia libre) y la búsqueda del bien común (inteligencia organizada). Es decir, la prevención de existencias parasitarias y el fomento de la diversidad y la tolerancia, procurando así el bienestar de todos en cuanto individualidades valiosas y no como simples partículas de una masa. En tal sentido subraya Dewey en Creative Democracy - The Task Before Us:

La democracia es la creencia en la capacidad de la experiencia humana para generar los fines y los métodos para promover una experiencia que habrá de crecer en orden a su propio enriquecimiento. Todas las otras formas de fe moral y social reposan sobre la idea de que la experiencia debe estar sujeta, hasta cierto punto, a alguna forma de control externo o alguna "autoridad" que intenta existir por fuera de los procesos de la experiencia. La democracia es la fe en que el proceso de la experiencia es más importante que cualquier resultado particular obtenido; así, los resultados especiales logrados solo alcanzan su valor último cuando son usados para enriquecer y ordenar el proceso en curso. (LW 14: 229)

Así entonces, la democracia es un proyecto educativo en sí mismo, en cuanto que se basa en una fe en el valor absoluto no negociable de la individualidad y, por ende, en una confianza en la enorme capacidad transformadora de la experiencia humana. Por tanto, aquellos fines y valores que desconozcan, desestimen o anulen dicha fe

5 Jürgen Habermas (1998), Richard Rorty (1996; 2001) y Axel Honneth (1999) han sido los filósofos que más han insistido en este carácter comunicativo, cooperativo y solidario de la democracia deweyana. 
devienen atrofias u obstáculos para todo aquello que se pueda denominar un ethos o una cultura democrática. La razón por la cual Dewey les considera atrofias es porque impiden la tarea de la democracia: "la creación de una experiencia más libre y más humana en la que todos participemos y a la cual todos contribuyamos" (Dewey, Creative Democracy - The Task Before Us, LW 14: 230).

\section{Conclusión}

La integración dinámica entre la individualidad, la libertad, la formación del punto de vista y la democracia, es el centro de gravedad del pensamiento deweyano, en la medida en que se constituye en el más efectivo antídoto al autoritarismo y al totalitarismo, promotores de existencias parasitarias. Ahora bien, la preocupación del pragmatista por estos temas se justifica en la medida en que estos enemigos de la democracia debilitan y anulan varios asuntos neurálgicos: primero, la pluralidad como punto de partida de la crítica y la oposición; segundo, las condiciones de libertad e igualdad para ejercer un genuino control social del poder y así participar en las transformaciones que a todos convienen; tercero, la capacidad de formación de los ciudadanos en virtudes como la prudencia, la tolerancia y la solidaridad, supuestos necesarios para la participación adecuada en el debate público; cuarto, el cultivo, la valoración y la promoción de la fuerza de la razón y no solo de la razón de la fuerza, debido a que los imperios de miedo y los regímenes autoritarios infantilizan a los individuos e impiden el florecimiento humano; y, quinto, la responsabilidad de los ciudadanos con la conformación de una inteligencia organizada y no simplemente dirigida por tutores, debido a que en muchos casos esto degenera en el desarrollo de personalidades apáticas (indiferentes) o antipáticas (saboteadoras o corrosivas).

De hecho, dichos enemigos de la forma de vida democrática son grandes maquinarias productoras de vidas masificadas, pues le temen al cultivo adecuado de las individualidades. Esto lo consiguen impidiendo el desarrollo y expresión del pensamiento crítico, o reduciéndolo al plano de la extrema vida privada inofensiva. Es decir, debido al temor a la formación, expresión y discusión de los puntos de vista diversos, optan por la represión, el adoctrinamiento y la violencia. Ahora bien, una vez se establecen estos regímenes las personas quedan en condiciones bastante desfavorables para emanciparse, en la medida en que se desdibuja el valor absoluto no negociable de la individualidad, ya que se le da mayor relevancia a los procedimientos, los dispositivos institucionales y las metas históricas hacia donde los líderes autoritarios quieren llevar al resto de las personas (Popper 1971). Asimismo, el pesimismo antropológico que subyace a muchos regímenes autoritarios y totalitarios conlleva a que se crea que los seres humanos son malos, egoístas e indisciplinados por naturaleza. Por esta razón, dichos regímenes no solo no promueven el florecimiento de la inteligencia como punto de vista informado y creativo, sino que además ponen bajo sospecha la agencia como libertad individual o capacidad de elegir y participar soberanamente para tener un control social transparente. En definitiva, los regímenes del miedo, que parten de la idea de que los ciudadanos son malos por naturaleza $\mathrm{y}$, por ende, que deben ser controlados con mano dura y de forma tutorial (como a pequeños salvajes), terminan por desestabilizar y anular el desarrollo de una inteligencia social-organizada que garantice una comunidad cooperadora, crítica, abierta y plural (Honneth 1999). 
En suma, lo que Dewey descubre detrás del autoritarismo y el totalitarismo es una profunda desconfianza en la naturaleza humana (Freedom and Culture, LW 13: 152-153), razón por la cual dichos regímenes suelen usar prácticas para ridiculizar, controlar, reprimir, censurar e, incluso, aniquilar la oposición. La apuesta que hace el pragmatista por la forma de vida democrática es una exaltación de la libertad de la inteligencia, gracias a la cual los seres humanos son un proyecto inacabado pero prometedor. Es decir, el camino elegido y las estrategias empleadas para lograr el inspirador ideal de la democracia contienen siempre el principio de la libertad de la inteligencia, la cual debe ser promovida y cultivada (educada), no perseguida y anulada (Pineda 2012, pp. 169-170). Esta libertad de la inteligencia debe cuidarse en cada punto de vista expresado en ámbitos como la academia, la prensa, la circulación cotidiana de información, las reuniones espontáneas de vecinos y familias, y las asambleas públicas. Subraya Dewey en What Is Democracy?:

Lo que el totalitarismo revela con asombrosa claridad es que el asunto central para una democracia es el del respeto por la libertad de la inteligencia; razón por la cual la democracia debe ponerse en contra de un irrespeto tan grande y poderoso, pues se puede dar su efectiva negación y supresión si sobreviene el carácter totalitario en las acciones, la política y la economía, aunque sea de manera pasiva. (LW 17: 473)

Ahora bien, la gran lección es que ni el totalitarismo ni la democracia pueden seguir siendo vistos como una simple realidad externa a los individuos, ya que cada persona tiene parte de la responsabilidad en la transformación de las condiciones sociales, políticas, económicas y culturales. Es decir, se hace indispensable contar con el esfuerzo por cambiar el statu quo, cultivando la propia individualidad como garantía para formar un punto de vista crítico, creativo y comprometido en un proceso de cooperación reflexiva (Honneth 1999). La democracia, en cuanto contraria a cualquier forma de autoritarismo y totalitarismo, solo se soporta en actitudes, sentimientos y acciones que forjen una personalidad que, al momento de ponerla en el plano público, defienda la participación, el debate de puntos de vista y la solidaridad para lograr acuerdos.

En definitiva, aquí se halla la principal diferencia entre la forma de vida democrática y otros modos de vida: en el ethos democrático las personas no se conforman con que otros individuos - salidos de la caverna- con recetas verdaderas e inteligencias superiores y privilegiadas definan lo que es bueno para todos $\mathrm{y}$, por tanto, decidan hacia dónde conducir a la sociedad en conjunto. En la democracia, tal como la entiende Dewey, la individualidad es la nota constitutiva por el valor único que tiene en sí misma la experiencia del mundo y la inteligencia de cada persona (incluso la menos instruida). Cada individualidad es valiosa porque es un aporte irremplazable al florecimiento de la sociedad, al hacerla más dinámica, plural, crítica y abierta a las mejoras. Por esta razón, a la individualidad no solo se le debe garantizar su expresión como inteligencia libre, sino también óptimas condiciones de educación, de tal forma que no degenere en un individualismo parasitario (indiferente o saboteador de los procesos sociales). Una cultura se engrandece y progresa cuando el fin de su sistema educativo es cultivar el pensamiento reflexivo de los individuos, mejorando la capacidad de pensar de manera libre y autónoma (Dewey, Individualism Old and New, LW 5: 41-123). Así, fomentando una adecuada educación de la individualidad se logra una inteligencia social-organizada, gracias a la cual se puede dar un progreso en las condiciones de bienestar, respeto, justicia y solidaridad. 


\section{Referencias bibliográficas}

Bernstein, R. (2010): Filosofía y democracia: John Dewey, Barcelona, Herder.

Castells, M. (2009): Comunicación y poder, Madrid, Alianza.

Dewey, J. (1976-1983): The Middle Works (MW) 1899-1924, edited by Jo Ann Boydston, Carbondale, Southern Illinois University Press, 15 vols.

Dewey, J. (1965): Teoría de la vida moral, trad. Rafael Castillo, México, Herrero Hermanos.

Dewey, J. (1969-1975): The Early Works (EW) 1882-1898, edited by Jo Ann Boydston, Carbondale, Southern Illinois University Press, 5 vols.

Dewey, J. (1981-1990): The Later Works (LW) 1925-1953, edited by Jo Ann Boydston, Carbondale, Southern Illinois University Press, 17 vols.

Emerson, R.W. (1928): Obras completas, trad. Francisco Gallach, Madrid, Imprenta de L. Rubio.

Festenstein, M. (1997): Pragmatism and Political Theory. From Dewey to Rorty, Chicago, University Chicago Press.

Festenstein, M. (2005): Dewey's Political Philosophy, Stanford Encyclopedia of Philosophy, http://plato.stanford.edu/entries/dewey-political

Habermas, J. (1970): “On systematically distorted communication”, Inquiry, 13 (1-4), 205218. doi: 10.1080/00201747008601590

Habermas, J. (1989): Teoría de la acción comunicativa, vol. II, Buenos Aires, Taurus.

Habermas, J. (1997): Conocimiento e interés, Madrid, Taurus.

Habermas, J. (1998): Facticidad y validez. Sobre el derecho y el Estado democrático de derecho en términos de teoría del discurso, Madrid, Trotta.

Honneth, A. (1999): "La democracia como cooperación reflexiva. John Dewey y la teoría de la democracia del presente", Estudios Políticos, 15, 81-106

James, W. (1984): Pragmatismo. Un nuevo nombre para viejos modos de pensar, trad. Luis Rodríguez, Madrid, Sarpe.

Lippmann, W. (1927): Phantom Public, Nueva York, Macmillan Co.

Maine, H. (1886): Popular government; four essays, New York, H. Holt and Co.

Mougan, C. (2016): "Dewey: el significado democrático de la primacía de los hábitos", Daimon 68, 85-100

Pineda, D. (2012): El individualismo democrático de John Dewey: reflexiones en torno a la construcción de una cultura democrática, Bogotá, Editorial Pontificia Universidad Javeriana.

Platón (1997): La República, trad. J. Pabón y M. Fernández, Madrid, Alianza.

Popper, K. (1971): The Open Society and Its Enemies, Princeton, Princeton University Press.

Rorty, R. (1996): Objetivity, relativism and truth, Philosophical Papers I, Cambridge, Cambridge University Press.

Rorty, R. (1997): ¿Esperanza o conocimiento? Una introducción al pragmatismo, Buenos Aires, Fondo de Cultura Económica.

Rorty, R. (2001): Contingencia, ironía y solidaridad, Barcelona, Paidós.

Sartori, G. (1998): Homo videns. La sociedad teledirigida, Madrid, Taurus.

Savage, D. (2002): John Dewey's liberalism: individual, community, and self-development, Carbondale, Southern Illinois University Press.

Van Dijk, T. (2003). Ideología y discurso. Una introducción multidisciplinaria, Barcelona, Ariel.

Van Dijk, T. (2012). Discurso y contexto. Una aproximación cognitive, Barcelona, Gedisa.

Vattimo, G. (1990): La sociedad transparente, Barcelona, Paidós.

Whitman, W. (1944): Perspectivas democráticas, trad. Luis Azua, Buenos Aires, Americalee. 